\title{
Data report: gas hydrate structural and compositional characterization by spectroscopic analysis, IODP Expedition $311^{1}$
}

\author{
K.C. Hester, ${ }^{2,3}$ C.A. Koh, ${ }^{2}$ S.F. Dec, ${ }^{2}$ and E.D. Sloan ${ }^{2}$
}

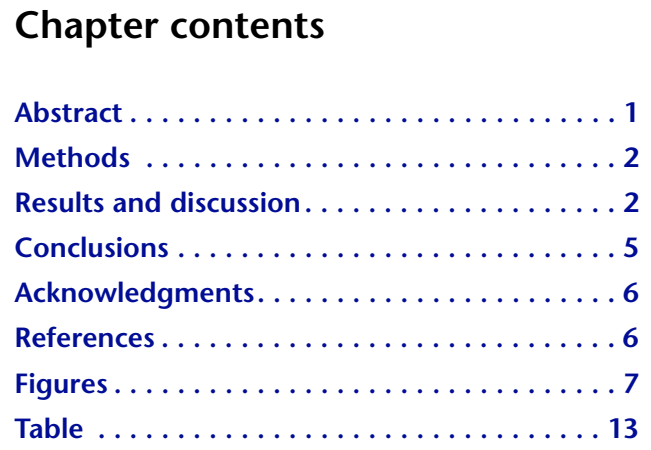

${ }^{1}$ Hester, K.C., Koh, C.A., Dec, S.F., and Sloan, E.D., 2008. Data report: gas hydrate structural and compositional characterization by spectroscopic analysis, IODP Expedition 311. In Riedel, M., Collett, T.S., Malone, M.J., and the Expedition 311 Scientists, Proc. IODP, 311: Washington, DC (Integrated Ocean Drilling Program Management International, Inc.).

doi:10.2204/iodp.proc.311.202.2008

${ }^{2}$ Center for Hydrate Research, Colorado School of Mines, Golden CO 80401, USA. Correspondence author: esloan@mines.edu

${ }^{3}$ Present address: Monterey Bay Aquarium Research Institute, 7700 Sandholdt Road, Moss Landing CA 95039, USA.

\begin{abstract}
Two gas hydrate cores from Integrated Ocean Drilling Program Expedition 311 Site U1328 (northern Cascadia margin) were analyzed for structural and compositional characterization. Gas hydrate was present mainly as nodules surrounded by sediment. The samples were recovered from 4.5 to 8.68 meters below seafloor using a conventional nonpressurized coring technique. Quenched in liquid nitrogen upon recovery, the gas hydrates were kept at cryogenic temperatures for sampling with Raman and nuclear magnetic resonance spectroscopy. Pure structure I (sI) methane gas hydrate was found in one sample and a methane-rich sI gas hydrate containing hydrogen sulfide was found in the second sample. Small local variations in the hydrogen sulfide amounts were shown. A hydration number of 6.08 was measured for both samples, in agreement with previous work with synthetic and recovered natural gas hydrates from similar locations. A method for determining the fraction of hydrate vs. ice using a Raman peak from water is given. This approach provides a possible tool to estimate sample degradation (conversion of gas hydrate to water + gas) as a result of recovery. Quantitative agreement between the methane cage occupancy ratios was shown for the nuclear magnetic resonance and Raman spectroscopic techniques for both sample sets, comprising pure methane and a mixture of methane + hydrogen sulfide.
\end{abstract}

\section{Introduction}

Gas hydrates are crystalline inclusion compounds made of water molecules that form cages. These cages trap low-molecular weight molecules, typically at high pressure and low temperature conditions. Gas hydrates are known to proliferate in the sediments of the continental slopes and the permafrost. The majority of these natural gas hydrates are composed of methane in the structure I (sI) lattice. The sI lattice unit cell consists of 46 waters in two cage types: two pentagonal dodecahedron $\left(5^{12}\right)$ and six tetrakaidecahedron $\left(5^{12} 6^{2}\right)$ cages. Molecules such as methane and hydrogen sulfide form this structure (Sloan and Koh, 2007).

Interest in natural gas hydrates has largely been driven by the vast quantities of methane they are estimated to contain. Current estimates of methane trapped in gas hydrate are $2.5 \times 10^{15}$ to $440 \times$ 
$10^{15} \mathrm{~m}^{3}$ at standard temperature and pressure (Milkov, 2004; Klauda and Sandler, 2005). In addition, the possible role of gas hydrates in climate change and as a geohazard has been the focus of numerous studies (Dickens, 2001; Kennett et al., 2003; Milkov et al., 2003). Structural and compositional characterization of natural gas hydrates is important to determine gas hydrate properties including pressure-temperature stability and thermal conductivity, both from energy recovery and geohazard aspects.

Integrated Ocean Drilling Program (IODP) Expedition 311 was performed in the northern Cascadia margin (see the "Expedition 311 summary" chapter). The goal of this program was to constrain geological models for the formation of gas hydrates. This includes both field measurements and recovery of samples for laboratory characterization. The contribution of this manuscript is to provide structural and compositional characterization with nuclear magnetic resonance (NMR) and Raman spectroscopy of two recovered gas hydrate samples. Characterization of gas hydrates from this area adds to the understanding of how these systems formed and the current state of the gas hydrates in the northern Cascadia margin.

\section{Methods}

\section{Raman spectroscopy}

For the Raman measurements, a Renishaw MK III Raman spectrometer was used, utilizing a $30 \mathrm{~mW}$ argon laser emitting green light at a wavelength of 514.53 $\mathrm{nm}$ as an excitation source. The light was transported through a $50 \mu \mathrm{m}$ optical fiber cable to the probe and was focused on the sample using a $20 \times$ objective lens.

Backscattered light was filtered using a 2400 grooves/ $\mathrm{mm}$ grating. The spectrometer was calibrated using the emission lines from neon, assuring an accuracy of $0.3 \mathrm{~cm}^{-1}$, while the spectral resolution was 4.5 $\mathrm{cm}^{-1}$. Raman spectra were analyzed using GRAMS/AI software from Galactic Industries Corporation. The gas hydrate was placed in a stainless steel sample holder, which was immersed in liquid nitrogen in order to keep the gas hydrate sample at $77 \mathrm{~K}$.

The outer surface of the gas hydrate samples was cleaved and placed in a cryostat maintained at $77 \mathrm{~K}$ under liquid nitrogen. Because Raman is a local technique (with the laser spot on the order of micrometers), various areas of the gas hydrate could be measured to detect any heterogeneity. The resulting spectra were deconvoluted in the same manner for all gas hydrate spectra with a mixed Gaussian and Lorentzian peak shape (Sum et al., 1997).

\section{NMR spectroscopy}

All ${ }^{13} \mathrm{C}$ magic angle spinning (MAS) NMR spectra were recorded on a Chemagnetics Infinity $400 \mathrm{NMR}$ spectrometer operating at $100.5 \mathrm{MHz}$ for ${ }^{13} \mathrm{C}$. A single-pulse ${ }^{13} \mathrm{C}$ MAS experiment with a pulse delay of $60 \mathrm{~s}$ was used to measure the sample. To verify this was sufficient for quantification, the same experiment was performed with a $120 \mathrm{~s}$ pulse delay, and the cage occupancies were in agreement with the 60 $s$ pulse delay case. This verified the pulse rate was sufficiently slow to record quantitative spectra. Proton decoupling of $\sim 50 \mathrm{kHz}$ was used during acquisition of the ${ }^{13} \mathrm{C}$ NMR signal.

The samples were cold-loaded into $7.5 \mathrm{~mm} \mathrm{ZrO}_{2}$ sleeves as powder and placed in the NMR Chemagnetics variable temperature (VT) probe at $\sim 248 \mathrm{~K}$. The samples were then cooled in $\sim 10 \mathrm{~s}$ intervals to $\sim 165$ $\mathrm{K}$. MAS between 2 and $4 \mathrm{kHz}$ was used. A $90^{\circ}$ pulse of $5 \mu \mathrm{s}$ was measured for the power settings used.

\section{Cage occupancy ratio calculation}

The gas hydrate cage occupancy ratio is defined as $\theta_{\mathrm{L}} / \theta_{\mathrm{S}}$, where $\theta$ is the absolute occupancy of a particular gas hydrate cage type and the subscripts $L$ and $S$ indicate the large and small cages, respectively $(\mathrm{L}=$ $5^{12} 6^{2}$ for $\mathrm{sI}, \mathrm{S}=5^{12}$ ). This occupancy ratio can be determined from the Raman or NMR spectrum by using $\theta_{L} / \theta_{S}=\left(A_{L} / 3\right) / A_{S}$, where $A$ is the area of the peak corresponding to the given cage type. $A_{L}$ is divided by 3 to account for the sI cage distribution.

\section{Results and discussion}

\section{Site U1328: Sample 311-U1328B-2H-HydCC (Hester, 2007)}

The first gas hydrate core (Sample 311-U1328B-2HHydCC, designated hereafter as Sample H1) was cored at IODP Hole U1328B in a water depth of $1267.8 \mathrm{~m}$. At this location, widespread carbonate deposits were observed on the seafloor (see the "Site U1328" chapter). The core, $1.7 \mathrm{~m}$ in length, was taken using a piston core, a conventional nonpressurized core, at a top depth of 4.5 meters below seafloor (mbsf) in Hole U1328B. Soupy sediment, likely because of gas hydrate dissociation during recovery, was observed upon recovery (see the "Site U1328" chapter). The core was recovered as pieces of sediment, mainly dark gray to greenish gray clay containing gas hydrate nodules (on the order of centimeters in size). Samples of the void headspace gas from the core were found to be primarily methane with 23,470 parts per million (ppm) $\mathrm{H}_{2} \mathrm{~S}$ and 4,375 ppm $\mathrm{CO}_{2}$ (see the "Site U1328" chapter). With the 
bottom water temperature around $276.65 \mathrm{~K}$ and a local geothermal gradient of $53.6 \pm 0.4 \mathrm{~K} / \mathrm{km}$, the in situ gas hydrate conditions for Sample H1 were around $276.9 \mathrm{~K}$ and $12.87 \mathrm{MPa}$. The approximate interstitial water salinity was determined to be 33.5.

For Raman analysis, six separate gas hydrate pieces (all on the order of $1 \mathrm{~cm}^{3}$ ) were chosen from Sample H1. Of each of these gas hydrate pieces, between two and four different spots were measured, resulting in 17 total Raman spectra collected. All spectra were collected for $50 \mathrm{~s}$ each. Figure F1 shows the spectral regions of interest. Only methane in the sI lattice was detected in all measurements of Sample H1. The main $v_{1}$ peaks for methane are present at $2900 \mathrm{~cm}^{-1}$ $\left(\mathrm{CH}_{4}\right.$ in the sI $\left.5^{12} 6^{2}\right)$ and $2912 \mathrm{~cm}^{-1}\left(\mathrm{CH}_{4}\right.$ in the sI $\left.5^{12}\right)$ with two minor peaks at 2570 and $3045 \mathrm{~cm}^{-1}$, indicating methane in a gas hydrate phase (Sum et al., 1997; Hester et al., 2007). It should be noted that although the $v_{1}$ peaks are shifted to lower wavenumbers by $3-4 \mathrm{~cm}^{-1}$ and the 3045 peak downshifted 9 $\mathrm{cm}^{-1}$ at $77 \mathrm{~K}$ versus $298 \mathrm{~K}$, there is no apparent temperature-induced shift of the $2570 \mathrm{~cm}^{-1}$ peak.

Using the peaks for methane at 2900 and $2912 \mathrm{~cm}^{-1}$, the relative composition in the gas hydrate can be determined. The methane occupancy ratio was found to be consistent throughout the Sample H1 core. Over 17 measurements, an average occupancy ratio was found to be $1.13 \pm 0.04$.

NMR spectroscopy on Sample H1 was also performed. Being a bulk technique versus the local nature of the Raman measurements, only one sample was measured (Fig. F2). As with the Raman work, only peaks for methane in the sI were measured at chemical shifts of $-6.2 \mathrm{ppm}\left(\mathrm{CH}_{4}\right.$ in the sI $\left.5^{12} 6^{2}\right)$ and $-4.1 \mathrm{ppm}$ $\left(\mathrm{CH}_{4}\right.$ in the sI 5 $\left.{ }^{12}\right)$ (Ripmeester and Ratcliffe, 1988). The methane occupancy ratio of $1.13 \pm 0.02$ was in excellent agreement with the Raman work.

\section{Site U1328: Sample 311-U1328E-2X-Hyd17}

The second gas hydrate core (Sample 311-U1328E2X-Hyd17, designated hereafter as Sample H2) was cored at IODP Hole U1328E in a water depth of $1264.7 \mathrm{~m}$ (see the "Site U1328" chapter). The core, $2.39 \mathrm{~m}$ in length, was taken using the extended core barrel at a top depth of 6.5 mbsf. Soupy sediments were also observed in this core along with a medium temperature anomaly, both indicating gas hydrate dissociation (see the "Site U1328" chapter). The core was recovered as a whole-round core with mainly dark gray to greenish gray clay sediment containing gas hydrate nodules (on the order of centimeters in size). The presence of $\mathrm{H}_{2} \mathrm{~S}$ was also detected upon the core recovery in the headspace gas using gas chroma- tography (see the "Site U1328" chapter). With the bottom water temperature at $\sim 276.65 \mathrm{~K}$ and a local geothermal gradient of $53.6 \pm 0.4 \mathrm{~K} / \mathrm{km}$, the in situ gas hydrate conditions were around $277.0 \mathrm{~K}$ and 12.83 MPa. Salinity was not determined for this core; however, a core in close vicinity (Section 311U1328E-2X-1) at a depth of 7.4 mbsf was determined to have an interstitial water salinity of 34.5.

Six gas hydrate pieces from Sample H2 were chosen for Raman spectroscopic analysis. As seen in Figure F3, along with peaks for sI $\mathrm{CH}_{4}$ similar to Sample H1, peaks for $\mathrm{H}_{2} \mathrm{~S}$ at $2593 \mathrm{~cm}^{-1}\left(\mathrm{H}_{2} \mathrm{~S}\right.$ in the sI $\left.5^{12} 6^{2}\right)$ and $2605 \mathrm{~cm}^{-1}\left(\mathrm{H}_{2} \mathrm{~S}\right.$ in the sI $\left.5^{12}\right)$ were detected (Dubessy et al., 1992). Small quantities of $\mathrm{H}_{2} \mathrm{~S}$ were present in every measurement of this methane-rich sI gas hydrate.

Compositional heterogeneity in Sample $\mathrm{H} 2$ was seen by slight variations in relative composition of $\mathrm{CH}_{4}$ to $\mathrm{H}_{2} \mathrm{~S}$. Although direct quantification of Raman gas hydrate peaks is not possible, the composition of hydrogen sulfide in the gas hydrate can be obtained, as a first approximation, correcting the peaks using relative normalized differential Raman scattering (RNDRS) cross sections available in the literature (Schrotter and Klockner, 1979). The RNDRS cross section for the $v_{1}$ peak of $\mathrm{CH}_{4}$ is 8.55 and 7 for the $v_{1}$ peak of $\mathrm{H}_{2} \mathrm{~S}$. The peak areas are corrected by dividing the measured peak area with the appropriate molecule and vibrational mode specific RNDRS cross section. With these corrections, the mole percent of $\mathrm{H}_{2} \mathrm{~S}$ in the 12 measurements varied from $1.94 \%$ to $2.47 \%$.

The methane occupancy ratio was also measured using both Raman and NMR spectroscopy. The average occupancy ratio from the Raman measurements was $1.16 \pm 0.02$. Excellent agreement was found with the NMR-determined occupancy ratio of $1.18 \pm 0.02$. Previous work has shown methane occupancy ratios were quantitative using Raman for pure methane gas hydrate but only qualitative when a second guest was present (Subramanian, 2002; Wilson et al., 2002). However, in the previous studies, the second guest was in much greater concentration than the few percent here. In the present work, the results show that small amounts of other guests still allow for quantification of $\mathrm{CH}_{4}$ by Raman spectroscopy. The average hydrogen sulfide relative cage occupancy was found from Raman spectroscopy to be $0.49 \pm 0.03$.

\section{Cage occupancy and hydration number}

Estimates of the absolute cage occupancies and hydration number from the experimentally determined occupancy ratios can be made (Ripmeester and Ratcliffe, 1988; Sum et al., 1997; Uchida et al., 1999) using 
the gas hydrate statistical mechanics model originally developed by van der Waals and Platteeuw (1959). The statistical mechanics model was derived assuming gas hydrates were an ideal solid solution, in which guest occupancy of the cages lowers the gas hydrate chemical potential. If the water lattice is not distorted and guest-guest interactions are negligible, the chemical potential of the sI gas hydrate $\left(\Delta \mu_{w H}\right)$ can be given as

$$
\Delta \mu_{\mathrm{wH}}-\Delta \mu_{\mathrm{w} \beta}=-\frac{\mathrm{RT}}{23}\left[3 \ln \left(1-\Sigma \theta_{\mathrm{L}, \mathrm{i}}\right)+\ln \left(1-\Sigma \theta_{\mathrm{S}, \mathrm{i}}\right)\right],
$$

where

$$
\begin{aligned}
\theta_{L, i}= & \text { occupancy of the large cage by component } \\
& \text { (i), } \\
\theta_{S, i}= & \text { occupancy of the small cage by component } \\
& \text { (i), and } \\
\Delta \mu_{\mathrm{w} \beta}= & \text { chemical potential of the hypothetical } \\
& \text { empty lattice. A generally accepted value } \\
& \text { for } \Delta \mu_{\mathrm{w \beta}} \text { is } 1297 \mathrm{~J} / \mathrm{mol} \text { (Handa and Tse, } \\
& 1986) .
\end{aligned}
$$

By combining the experimentally determined occupancy ratios and Equation 1, it is possible to solve for absolute cage occupancies. These can be used to solve for the hydration number, $n$, such that

$$
n=\frac{23}{3 \Sigma \theta_{L, i}+\Sigma \theta_{S, i}},
$$

which gives the ratio of water molecules to guest molecules in the gas hydrate. These experimentally determined cage occupancies and hydration numbers can then be compared with predictions from gas hydrate prediction programs, in this case CSMGem, which incorporates Gibbs energy minimization to eliminate the assumptions in the original van der Waals and Platteeuw model (Ballard and Sloan, 2002).

To solve for occupancies in Equation 1, quantitative experimental occupancy ratios are needed. Although NMR is inherently quantitative, Raman intensities rely on polarizability theory with parameters that are not trivial to determine (Placzek, 1934), leading to a more qualitative nature. However, cross-calibration with NMR has shown quantitative Raman methane cage occupancy ratios for pure methane gas hydrate (Subramanian, 2002; Wilson et al., 2002; Hester, 2007) and, in this study, with small amounts of $\mathrm{H}_{2} \mathrm{~S}$ present.

For Sample H1, only methane was detected. The experimentally determined occupancy ratio from Raman was $1.13 \pm 0.04$, in agreement with NMR (1.13 \pm $0.02)$. The $5^{12} 6^{2}$ was almost fully occupied (0.974) and the $5^{12}$ cage had an occupancy of 0.862 ; this resulted in a hydration number of $6.08 \pm 0.04$. Using the in situ conditions $(276.9 \mathrm{~K}, 12.78 \mathrm{MPa}, \mathrm{S}=33.5)$, the results of a flash calculation performed with
CSMGem yields large and small cage occupancies of 0.961 and 0.873 , respectively, and a hydration number of 6.13; these values are in good agreement with the experiment.

For Sample H2, both methane and hydrogen sulfide were present. To experimentally determine absolute cage occupancies and hydration numbers, the assumption that RNDRS cross sections can be used to estimate the gas hydrate composition was used. The mole fraction $\mathrm{H}_{2} \mathrm{~S}$ determined using this method for the six samples measured and absolute cage occupancies and hydration numbers calculated using Equations 1 and 2 are listed in Table T1. CSMGem calculations using the in situ conditions $(277.0 \mathrm{~K}$, $12.83 \mathrm{MPa}, \mathrm{S}=34.5$ ) are also summarized in Table T1. Even with the assumptions made, both experimentally determined occupancies and the calculations agreed well. It should be noted that $\mathrm{H}_{2} \mathrm{~S}$ has a greater occupancy in the $5^{12}$ cage $(2.9 \%-3.8 \%)$ versus the $5^{12} 6^{2}(1.5 \%-1.9 \%)$, both experimentally and calculated, possibly because of its greater stabilizing effect of the $5^{12}$ cage over methane.

For Samples $\mathrm{H} 1$ and $\mathrm{H} 2$, the average hydration number was $6.08 \pm 0.04$ and $6.08 \pm 0.02$, respectively. Recent work on recovered northern Cascadia margin gas hydrates (Lu et al., 2005) yielded a hydration number of $6.1 \pm 0.1$, very similar to the results of this work. Laboratory work using the combination of spectroscopic occupancy ratios and statistical mechanics have obtained values including $6.05 \pm 0.06$ (Ripmeester and Ratcliffe, 1988), $6.04 \pm 0.03$ (Sum et al., 1997), and $6.2 \pm 0.3$ (Uchida et al., 1999) for synthetic and natural methane gas hydrates. Careful direct laboratory hydration number measurements of synthetic methane gas hydrate have shown values of $5.99 \pm 0.07$ (Circone et al., 2005) and $6.00 \pm 0.01$ (Handa, 1986). The results from the synthetic samples are in good agreement with the recovered natural samples.

With known formation conditions, natural methane gas hydrates are structural and compositional analogs to laboratory samples as expected from thermodynamics. In addition, current statistical mechanics methods are able to predict the composition of these gas hydrates very well. However, multicomponent natural gas hydrates, such as those from thermogenic sources, still pose challenges, such as sample heterogeneity with mixed structures and varying compositions, and warrant future study.

\section{Presence of $\mathrm{H}_{2} \mathrm{~S}$}

It was indicated by the shipboard party that $\mathrm{H}_{2} \mathrm{~S}$ was detected in association with Samples H1 and H2. The spectroscopic measurements on the samples show 
that only Sample $\mathrm{H} 2$ contained $\mathrm{H}_{2} \mathrm{~S}$. It was noted that in the upper part of Hole U1328B (from which Sample $\mathrm{H} 1$ was recovered) dangerous levels of $\mathrm{H}_{2} \mathrm{~S}$ were detected (see the "Site U1328" chapter). Because some sample dissociation occurred during recovery, this work is inconclusive as to whether $\mathrm{H}_{2} \mathrm{~S}$ was present in situ in the gas hydrate from Sample H1.

\section{Estimates of sample degradation due to recovery}

Because these gas hydrate samples were from areas where temperatures would not allow for water ice, measurement of ice in quenched samples under liquid nitrogen can be attributed to the dissociation of gas hydrate or other sources, such as surrounding pore waters. Indication of gas hydrate dissociation was present with observation of a "soupy" texture in the recovered core. Raman measurements of the water phase could possibly be used to distinguish between gas hydrate and ice phases and assess sample degradation.

Figure F4 shows the Raman spectra for water in a synthetic sI gas hydrate and the ice phase at $77 \mathrm{~K}$. The most intense $\mathrm{O}-\mathrm{H}$ stretching peak for water is found at $3076 \mathrm{~cm}^{-1}$ for sI gas hydrate, whereas it is shifted $8 \mathrm{~cm}^{-1}$ to $3084 \mathrm{~cm}^{-1}$ for ice. A smaller shift between sI gas hydrate and ice was observed for the weaker water peak (3207 versus $3210 \mathrm{~cm}^{-1}$ ). For further analysis, the peak at $3076 \mathrm{~cm}^{-1}$ for sI and 3084 $\mathrm{cm}^{-1}$ for ice were used because they showed the greatest shift between phases. The shift of this peak can be used to determine if ice is present along with gas hydrate. When comparing the area of the $\mathrm{C}-\mathrm{H}$ methane peaks to the O-H water peak, Figure F5A shows that the ratio of water to methane can vary significantly. The most probable explanations could be either (1) the water peak was a mixture of sI and ice (caused by degradation during recovery and/or frozen pore water during quenching) or (2) the hydration number (ratio of water to gas hydrate guest) of the gas hydrate was variable. Figure F5B shows that for the gas hydrate spectra with a greater waterto-methane ratio, the $\mathrm{O}-\mathrm{H}$ stretching peak actually shifted to $3078 \mathrm{~cm}^{-1}$. This indicates that a mixture of sI and ice was the cause of the variation in the waterto-methane ratio, not a significant difference in the hydration number.

For these measurements at $77 \mathrm{~K}$, the most intense Raman peak for pure ice was at $3084 \mathrm{~cm}^{-1}$ with a full width at half maximum (FWHM) of $26.5 \mathrm{~cm}^{-1}$ and $3076 \mathrm{~cm}^{-1}$ with a FHWM of $29.8 \mathrm{~cm}^{-1}$ for pure sI methane gas hydrate. Both peaks were best fit with a
Lorentzian peak shape. In order to estimate the fraction of ice present, two Lorentzian peaks with the Raman peak characteristics (peak position and FWHM) of ice and the sI methane gas hydrate, respectively, were calculated and their relative intensities were varied. Summing the intensities of these two peaks over $3000-3150 \mathrm{~cm}^{-1}$ resulted in a single peak with a Raman shift between 3076 and 3084 $\mathrm{cm}^{-1}$, based on the relative peak intensities. If the RNDRS cross sections for water as ice and sI gas hydrate were assumed to be similar, this resulted in a correlation between the Raman shift of the water peak and the mole percent sI gas hydrate measured as shown in Figure F6.

To evaluate this approach of using the Raman shift to determine the amount of sI gas hydrate measured, the water peak in spectra of the IODP gas hydrates was fit between 3000 and $3150 \mathrm{~cm}^{-1}$ with two Lorentzian peaks constraining the wavenumber and FWHM width based on pure sI methane gas hydrate and ice. The resulting peak areas were then used to estimate the molar percentage of gas hydrate measured. As shown in Figure F6, good agreement was obtained with the two-Lorentzian technique described above. This approach allows for a very straightforward estimate of the sample degradation for recovered sI methane gas hydrate. In addition, this approach could be applied to laboratory samples for a rapid estimate of gas hydrate conversion. However, in the natural samples, it needs to be recognized that the water ice present in the quenched samples could have come from other sources, such as frozen pore waters.

\section{Conclusions}

Gas hydrates from two cores at Expedition 311 Site U1328 were measured with Raman and NMR spectroscopy. Both samples were sI methane gas hydrate with one containing small amounts of $\mathrm{H}_{2} \mathrm{~S}$. Interestingly, in both cases, $\mathrm{H}_{2} \mathrm{~S}$ was detected in the void gas headspace of the recovered core. It is not clear why $\mathrm{H}_{2} \mathrm{~S}$ was present in only one of the samples.

Cage occupancies and hydration numbers compared well with predictions from a statistical thermodynamic gas hydrate program and other measurements on natural methane gas hydrates. Raman spectroscopy has been shown to give quantitative methane cage occupancies even when a small amount of a second component is present in the gas hydrate. In addition, water Raman peaks were used to provide a possible estimate to the degree of sample degradation resulting from unstable conditions during recovery. 


\section{Acknowledgments}

We thank the Integrated Ocean Drilling Program and all involved in Expedition 311, especially Michael Riedel and Tim Collett, for making these samples available to us. The authors thank $\mathrm{H}$. Lu for his helpful review of this work. K. Hester was supported through National Undersea Research Program grant UAF03-0098.

\section{References}

Ballard, A.L., and Sloan, E.D., Jr., 2002. The next generation of hydrate prediction, I. Hydrate standard states and incorporation of spectroscopy. Fluid Phase Equilib., 194-197:371-383. doi:10.1016/S0378-3812(01)00697-5

Circone, S., Kirby, S.H., and Stern, L.A., 2005. Direct measurement of methane hydrate composition along the hydrate equilibrium boundary. J. Phys. Chem. B, 109(19):9468-9475. doi:10.1021/jp0504874

Dickens, G., 2001. On the fate of past gas: what happens to methane released from a bacterially mediated gas hydrate capacitor? Geochem., Geophys., Geosyst., 2(1). doi:10.1029/2000GC000131

Dubessy, J., Boiron, M.C., Moissette, A., Monnin, C., and Stretenskaya, N., 1992. Determination of water, hydrates and $\mathrm{pH}$ in fluid inclusions by micro-Raman spectrometry. Eur. J. Mineral., 4(5):885-894.

Handa, Y.P., 1986. Compositions, enthalpies of dissociation, and heat capacities in the range 85 to $270 \mathrm{~K}$ for clathrate hydrates of methane, ethane, and propane, and enthalpy of dissociation of isobutane hydrate, as determined by a heat-flow calorimeter. J. Chem. Thermodyn., 18(10):915-921. doi:10.1016/ 0021-9614(86)90149-7

Handa, Y.P., and Tse, J.S., 1986. Thermodynamic properties of empty lattices of structure I and structure II clathrate hydrates. J. Phys. Chem., 90(22):5917-5921. doi:10.1021/j100280a092

Hester, K.C., 2007. Probing hydrate stability and structural characterization of both natural and synthetic clathrate hydrates [Ph.D. thesis]. Colorado School of Mines, Golden.

Hester, K.C., Dunk, R.M., White, S.N., Brewer, P.G., Peltzer, E.T., and Sloan, E.D., 2007. Gas hydrate measurements at Hydrate Ridge using Raman spectroscopy. Geochim. Cosmochim. Acta, 71(12):2947-2959. doi:10.1016/ j.gca.2007.03.032

Kennett, J.P., Cannariato, K.G., Hendy, I.L., and Behl, R.J., 2003. Methane Hydrates in Quaternary Climate Change: The Clathrate Gun Hypothesis. Spec. Publ._Am. Geophys. Union.

Klauda, J.B., and Sandler, S.I., 2005. Global distribution of methane hydrate in ocean sediment. Energy Fuels, 19(2):459-470. doi:10.1021/ef049798o
Lu, H., Moudrakovski, I., Riedel, M., Spence, G., Dutrisac, R., Ripmeester, J., Wright, F., and Dallimore, S., 2005. Occurrences and structural characterizations of gas hydrates associated with a cold vent field, offshore Vancouver Island. J. Geophys. Res., 110(B10):B10204. doi:10.1029/2005JB003900

Milkov, A.V., 2004. Global estimates of hydrate-bound gas in marine sediments: how much is really out there? Earth-Sci. Rev., 66(3-4):183-197. doi:10.1016/ j.earscirev.2003.11.002

Milkov, A.V., Claypool, G.E., Lee, Y.-J., Xu, W., Dickens, G.R., Borowski, W.S., and ODP Leg 204 Scientific Party, 2003. In situ methane concentrations at Hydrate Ridge offshore Oregon: new constraints on the global gas hydrate inventory from an active margin. Geology, 31(10):833-836. doi:10.1130/G19689.1

Placzek, G., 1934. Handbuch der Radiologie: Leipzig (Akademische Verlagsgesellschaft).

Ripmeester, J.A., and Ratcliffe, C.I., 1988. Low-temperature cross-polarization/magic angle spinning ${ }^{13} \mathrm{C}$ NMR of solid methane hydrates: structure, cage occupancy, and hydration number. J. Phys.Chem., 92(2):337-339. doi:10.1021/j100313a018

Schrotter, H.W., and Klockner, H.W., 1979. Raman scattering cross sections in gases and liquids. In Weber, A. (Ed.), Raman Spectroscopy of Gases and Liquids: Berlin (Springer-Verlag), 3:123-166.

Sloan, E.D., and Koh, C.A., 2007. Clathrate Hydrates of Natural Gases, 3rd ed.: Boca Raton (CRC Press).

Subramanian, S., 2002. Measurements of clathrate hydrates containing methane and ethane using Raman spectroscopy [Ph.D. thesis]. Colorado School of Mines, Golden.

Sum, A.K., Burruss, R.C., and Sloan, E.D., Jr., 1997. Measurement of clathrate hydrates via Raman spectroscopy. J. Phys. Chem. B, 101(38):7371-7377. doi:10.1021/ jp970768e

Uchida, T., Hirano, T., Ebinuma, T., Narita, H., Gohara, K., Mae, S., and Matsumoto, R., 1999. Raman spectroscopic determination of hydration number of methane hydrates. AIChE J., 45(12):2641-2645. doi:10.1002/ aic. 690451220

van der Waals, J.H., and Platteeuw, J.C., 1959. Clathrate solutions. In Prigogine, I. (Ed.), Advances in Chemical Physics, Vol. 2: New York (Wiley and Sons), 1-57. doi:10.1002/9780470143483.ch1

Wilson, L.D., Tulk, C.A., and Ripmeester, J.A., 2002. Instrumental techniques for the investigation of methane hydrates: cross-calibrating NMR and Raman spectroscopic data [Fourth International Conference on Gas Hydrates, Yokohama, Japan, 19-23 May 2002].

Intial receipt: 6 July 2007

Acceptance: 30 October 2007

Publication: 6 March 2008

MS 311-202 
Figure F1. Representative Raman spectrum of hydrate collected from Sample 311-U1328B-2H-HydCC (Sample $\mathrm{H} 1)$ at $77 \mathrm{~K}$ for $50 \mathrm{~s}(5 \mathrm{~s} \times 10)$.

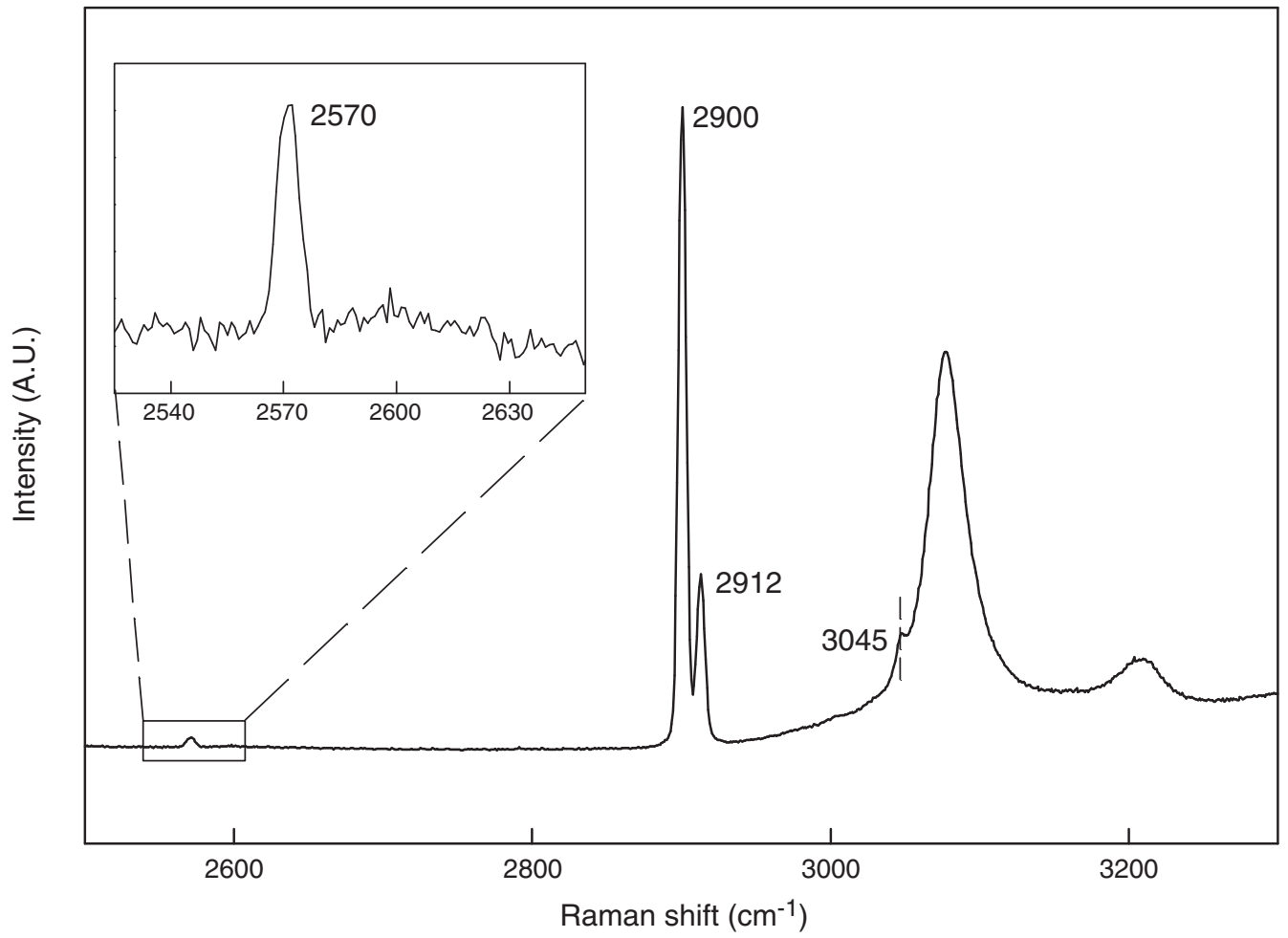


Figure F2. Representative NMR spectrum of hydrate collected from Sample 311-U1328B-2H-HydCC (Sample H1).

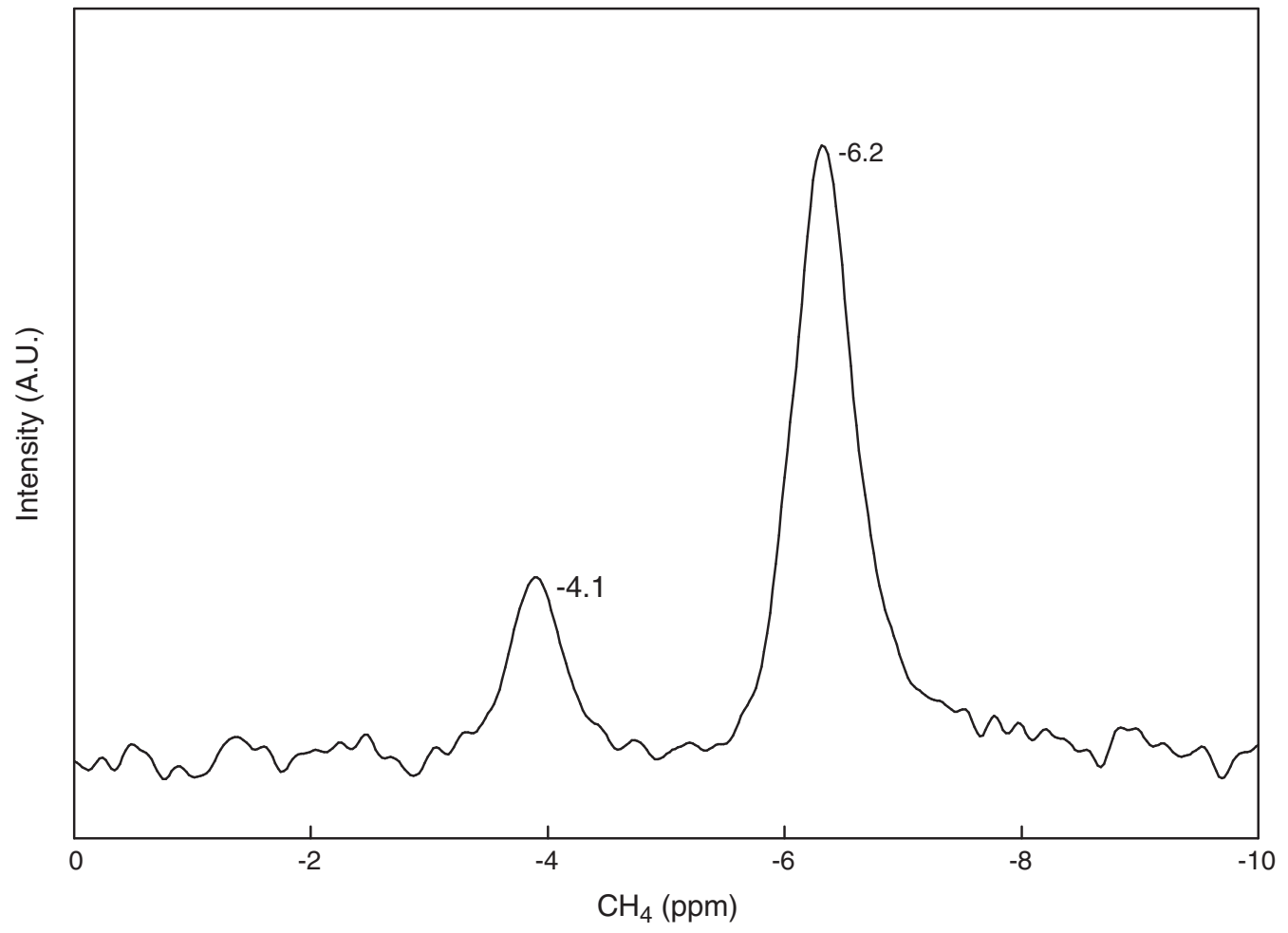


Figure F3. Representative Raman spectrum of hydrate collected from Sample 311-U1328E-2X-Hyd17 (Sample $\mathrm{H} 2)$ at $77 \mathrm{~K}$ for $50 \mathrm{~s}(5 \mathrm{~s} \times 10)$.

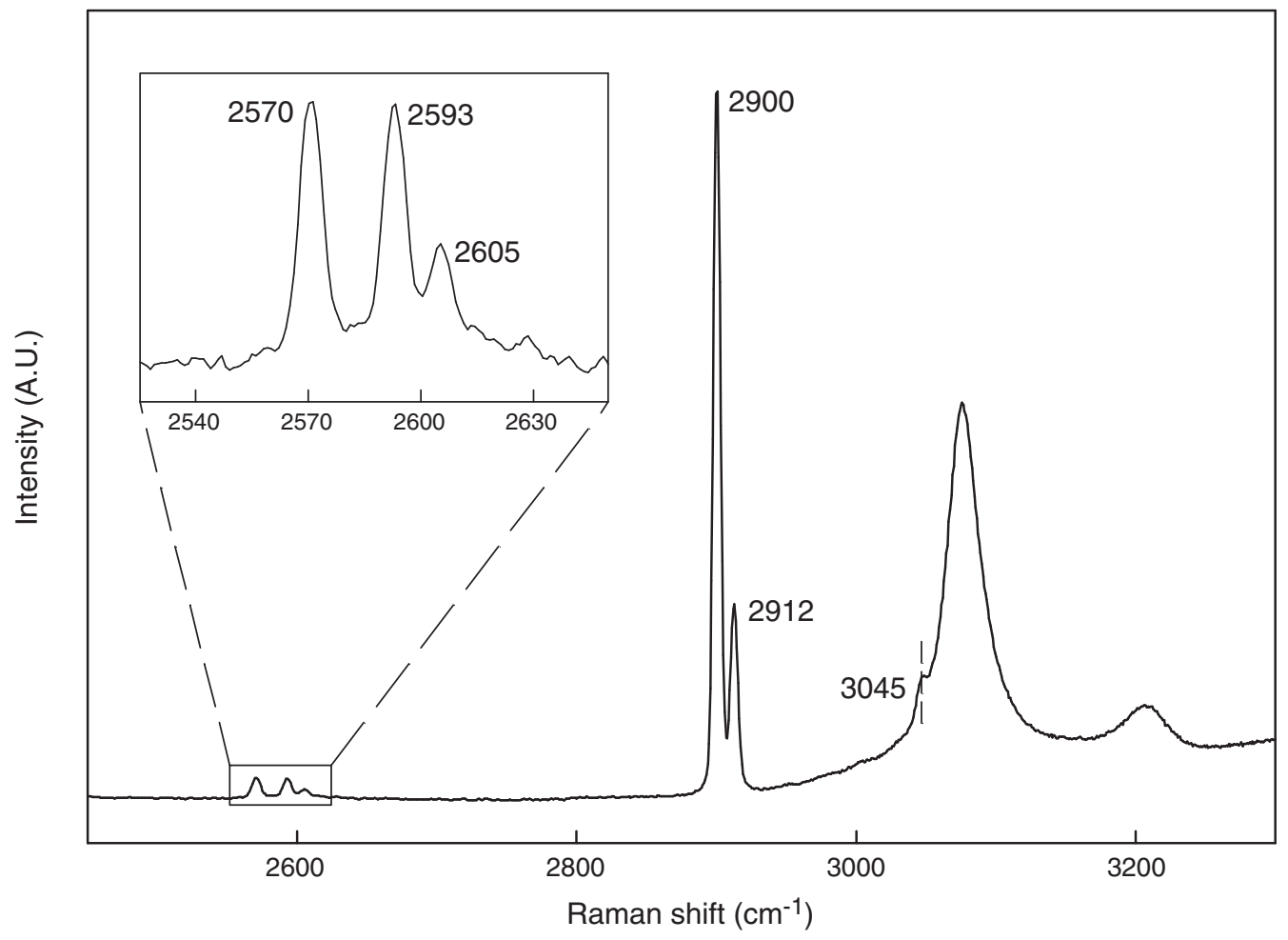


Figure F4. Raman spectra of synthetic sI methane hydrate and water ice collected at $77 \mathrm{~K} .{ }^{*}=$ vibrational modes from methane.

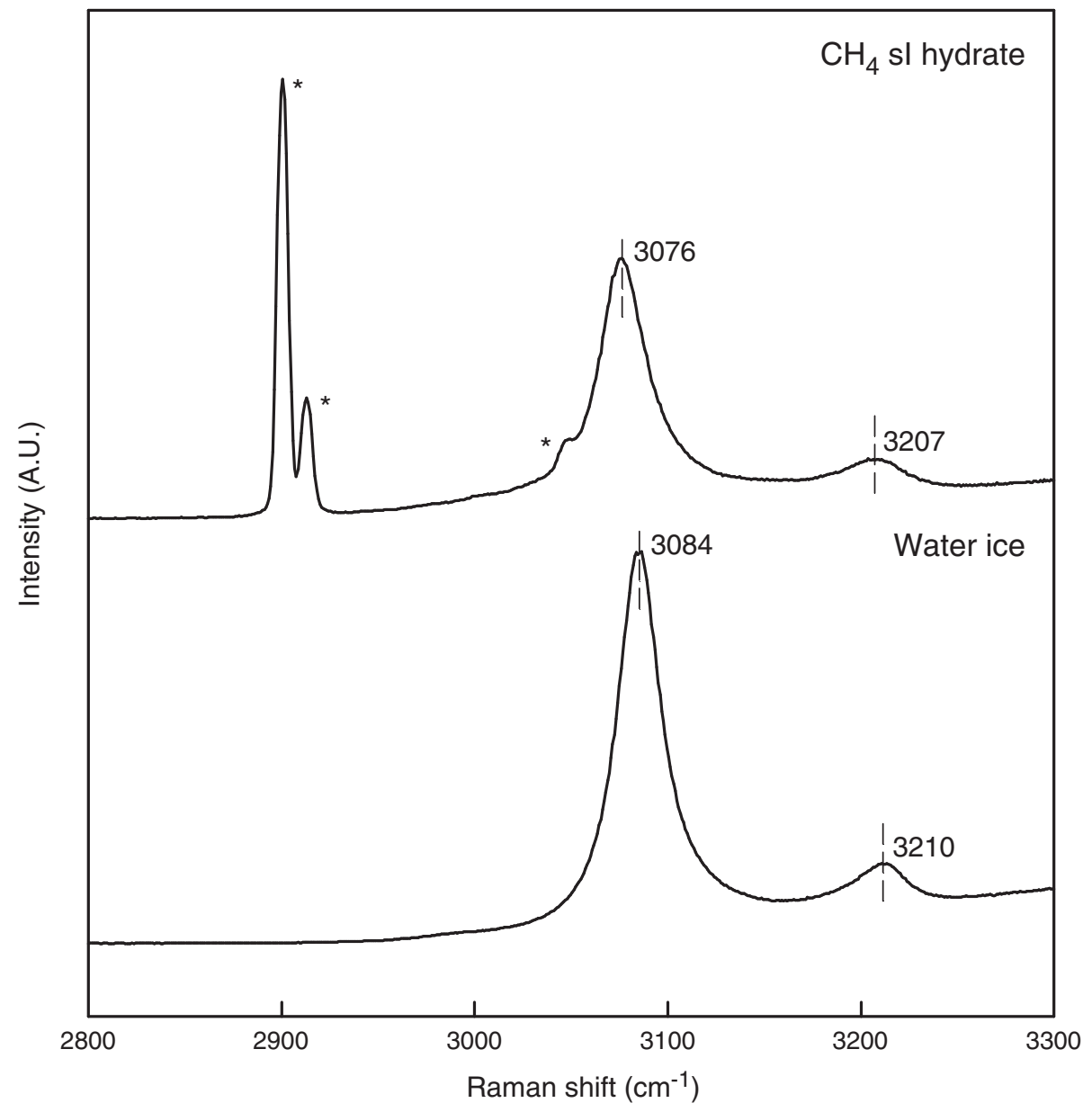


Figure F5. Raman spectra from Sample 311-U1328B-2H-HydCC (Sample H1). A. Two spectra normalized to methane peaks. B. Water stretching peak for two hydrate spectra and water ice.

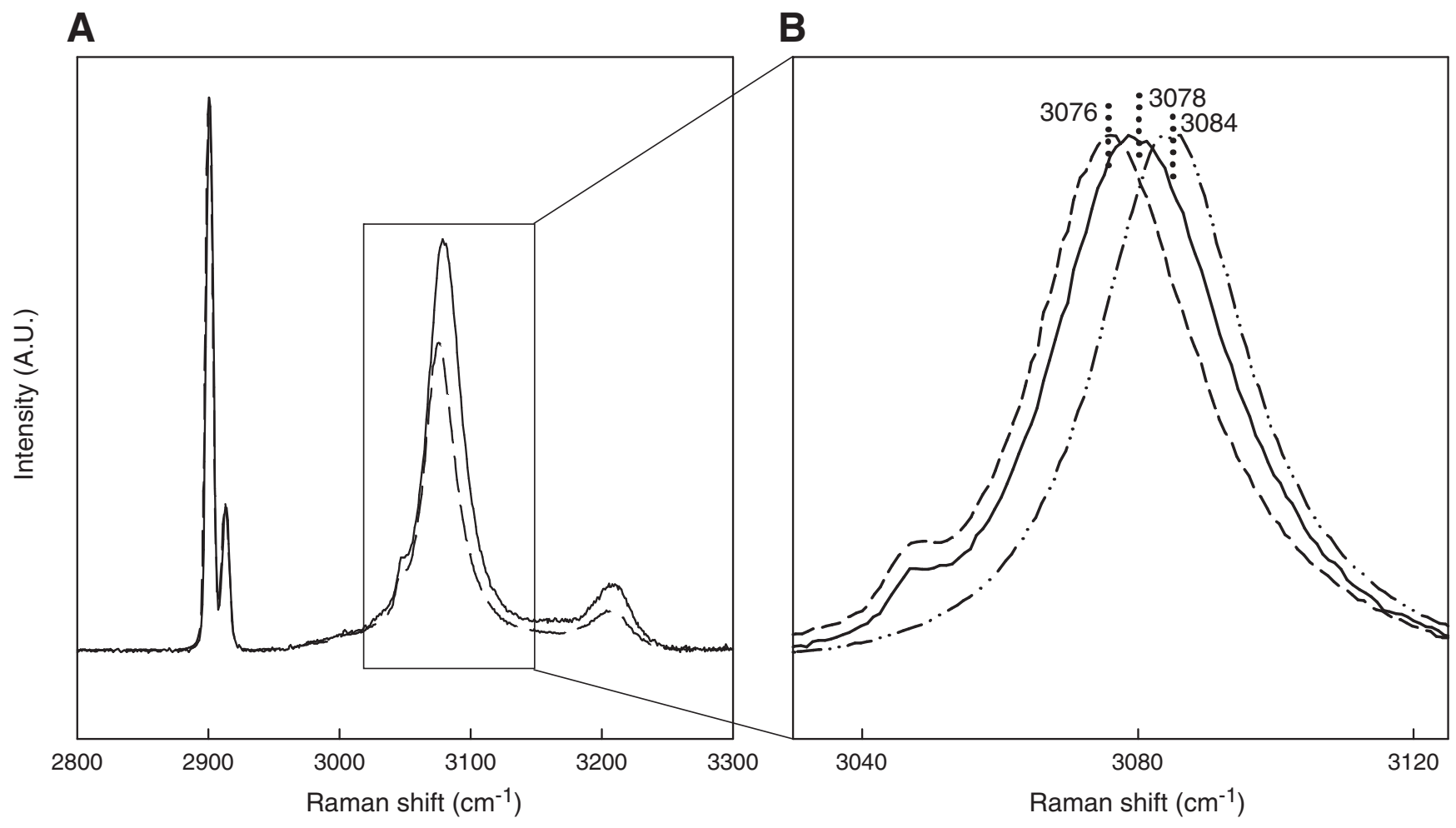


Figure F6. Molar percentage sI methane hydrate as a function of the wavenumber of the most intense Raman peak of water at $77 \mathrm{~K}$. Line = method of combining two Lorentzian peaks, squares $=$ experimental deconvolution of Raman water peak using two Lorentzian peaks with characteristics of pure sI hydrate and ice phases.

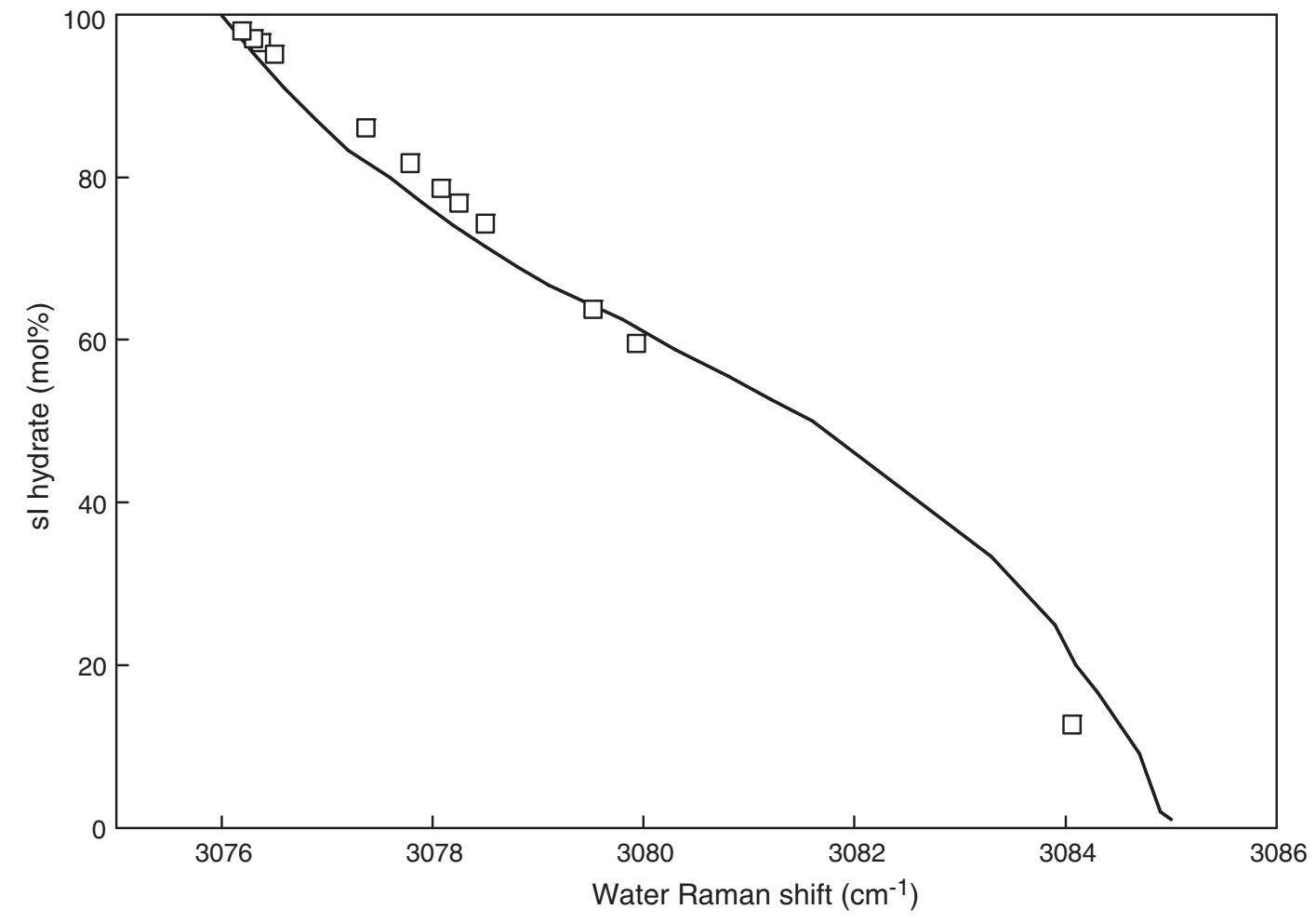


Table T1. Experimentally determined absolute occupancies and hydration numbers, Sample 311-U1328E-2XHyd17 (Sample H2).

\begin{tabular}{|c|c|c|c|c|c|c|c|}
\hline \multirow{2}{*}{$\begin{array}{c}\mathrm{CH}_{4} \\
(\mathrm{~mol} \%)\end{array}$} & \multicolumn{3}{|c|}{ Methane } & \multicolumn{3}{|c|}{ Hydrogen sulfide } & \multirow{2}{*}{$\begin{array}{c}\text { Hydration } \\
\text { number }\end{array}$} \\
\hline & Exp. $\theta_{\mathrm{L}} / \theta_{\mathrm{S}}$ & $\theta_{\mathrm{L}}$ & $\theta_{\mathrm{s}}$ & Exp. $\theta_{L} / \theta_{S}$ & $\theta_{\mathrm{L}}$ & $\theta_{\mathrm{s}}$ & \\
\hline \multicolumn{8}{|l|}{ Raman } \\
\hline 97.53 & 1.14 & 0.954 & 0.839 & 0.50 & 0.019 & 0.038 & 6.06 \\
\hline 97.69 & 1.19 & 0.958 & 0.806 & 0.47 & 0.017 & 0.036 & 6.10 \\
\hline 97.83 & 1.15 & 0.957 & 0.833 & 0.48 & 0.016 & 0.034 & 6.07 \\
\hline 97.84 & 1.17 & 0.958 & 0.818 & 0.52 & 0.017 & 0.032 & 6.10 \\
\hline 98.01 & 1.13 & 0.958 & 0.848 & 0.47 & 0.015 & 0.031 & 6.06 \\
\hline 98.06 & 1.15 & 0.959 & 0.833 & 0.52 & 0.015 & 0.029 & 6.08 \\
\hline \multicolumn{8}{|l|}{ CSMGem } \\
\hline 97.53 & & 0.945 & 0.837 & & 0.017 & 0.043 & 6.11 \\
\hline 97.69 & & 0.946 & 0.839 & & 0.016 & 0.040 & 6.11 \\
\hline 97.83 & & 0.948 & 0.843 & & 0.015 & 0.038 & 6.10 \\
\hline 97.84 & & 0.948 & 0.843 & & 0.015 & 0.038 & 6.10 \\
\hline 98.01 & & 0.949 & 0.846 & & 0.013 & 0.035 & 6.10 \\
\hline 98.06 & & 0.949 & 0.847 & & 0.013 & 0.034 & 6.10 \\
\hline
\end{tabular}

Note: CSMGem calculations are from in situ conditions. 